\title{
Understanding the socio-structural context of high HIV transmission in kasensero fishing community, South Western Uganda
}

Muhamadi Lubega ${ }^{1,2,3,4^{*}}$, Neema Nakyaanjo ${ }^{1}$, Sumaya Nansubuga ${ }^{3}$, Edgar Hiire ${ }^{1}$, Godfrey Kigozi ${ }^{1}$, Gertrude Nakigozi ${ }^{1}$, Tom Lutalo ${ }^{1}$, Fred Nalugoda', David Serwadda', Ronald Gray ${ }^{1,5}$, Maria Wawer ${ }^{1,5}$,

Caitlin Kennedy ${ }^{5}$ and Steven James Reynolds ${ }^{1,4,5}$

\begin{abstract}
Background: In Kasensero fishing community, home of the first recorded case of HIV in Uganda, HIV transmission remains high with an incidence of 4.3 and 3.1 per 100 person-years in women and men, respectively, and an HIV prevalence of $44 \%$, reaching up to $74 \%$ among female sex workers. We explored the social contextual factors for the high HIV transmission at Kasensero to inform future policy and preventive interventions.

Methods: We conducted 20 in-depth interviews, including both HIV positive and HIV negative respondents, and 12 focus-group discussions involving a total of 92 respondents from the Kasensero fishing community from April-September 2014. Content analysis was performed to identify recurrent themes.

Results: Our findings suggest that the high HIV transmission in Kasensero is a complex function of eight themes including; positive/negative attitudes about HIV and combination HIV prevention such as the demand for services versus ART/circumcision disinhibition; HIV depository; Multiple partners; Frequent unprotected sex; Clothing; Parental behaviors; Pressure within the sex industry; and Cross generational sex.

Conclusions: The current combination HIV prevention services by the RHSP need to be enhanced with more government involvement including ensuring sustainable supply of ART and circumcision services since they are reportedly highly demanded. Community involvement through the engagement of popular peers could also help in the campaign to change the HIV predisposing culture, misconceptions and risky social norms of the population. Social Context HIV Transmission Fishing Community.
\end{abstract}

\section{Background}

Despite national efforts to reduce HIV transmission, HIV remains widespread among fishing communities in Uganda [1]. In Kasensero fishing community (around lake Victoria) south western Uganda, HIV prevalence is 44.3 \% (74.5 \% among female bar workers), and HIV incidence is $\sim 4.3$ / 100 person-years among women and $\sim 3.1 / 100$ personyears among men [2]. This prevalence is twice as high

\footnotetext{
* Correspondence: dlmuhamadi@yahoo.co.uk

${ }^{1}$ Rakai Health Sciences Program, Old Bukoba road, PO Box 279, Kalisizo, Uganda

${ }^{2}$ Division of Global Health, IHCAR, Department of Public Health Sciences, Karolinsika Institutet, PO Box 1717007, Stockholm, Sweden

Full list of author information is available at the end of the article
}

compared to the average HIV prevalence (22\%) in fishing communities around lake Victoria in Uganda and six times higher compared to the national HIV prevalence of $7.2 \%$ $[3,4]$. Like other key populations, fishing communities contribute disproportionately to the national HIV burden and are at greater risk of infection than the general population. They also play a leading role in spreading the infection to the general population $[5,6]$.

The government of Uganda is providing combination HIV prevention (CHP) (biomedical, behavioral and socialstructural services to reduce the new HIV infections in fishing communities and other key population [7]. In the same line, Rakai health sciences program (RHSP) has been 
providing CHP services to the Kasensero fishing community for over five years now. The persistent high HIV prevalence and incidence in the Kasensero community is, however, still a cause for great concern and a clear contextual understanding of the status quo is required for generation of more enhanced approaches to improving the current CHP services to the community.

Research in settings similar to Kasensero fishing community in Malawi, Tanzania, Zambia, and other sites around lake Victoria basin has shown that contextual vulnerabilities to HIV acquisition (lack of HIV awareness, transactional sex and health system deficiencies among others) are a function of the social and cultural norms, values, networks and structural settings of a particular community ([8-10]. Similar research has also shown that these contextual vulnerabilities also operate in concert with individual's behaviors and practices to influence the HIV epidemics in those particular settings [9-12]. It would be exigent, however, to generalize or transfer these contextual underpinnings from these studies/settings to Kasesnsero fishing community for two reasons; The HIV prevalence/ incidence in Kasensero is almost twice as high as other fishing communities around lake Victoria. Secondly, Kasensero fishing community is the site where the first case of HIV was diagnosed in Uganda and the HIV/ART awareness are presumably high. Based on the social ecological model of behavior, we therefore sought to explore what social-behavioral contexts can individually or in combination explain the very high and persistent HIV prevalence/incidence in Kasensero compared to other fishing sites. The socio-ecological model (SEM) is based on the intertwined relationship between the individual and the environment. The model asserts that individual behavior is not only a function of a person's individual knowledge, attitude, perceptions among others but also the environment in which he/she lives. The model caters for the different intertwinned levels of an individual's environment from intrapersonal (biological, psychological), interpersonal (social, cultural, attitudinal), organizational, community, physical environmental and policy outlines or guidelines as centres for behavioral actions or change [13-17].

\section{Methods}

\section{Study setting and population}

Between April and September 2014, we conducted this study at the Kasensero fishing community Rakai district south western Uganda approximately $200 \mathrm{~km}$ from the capital city Kampala. The community constitutes a population of approximately 15,000 . The majority of the population is mobile and depends directly or indirectly on fishing. Community members include fishermen, boat owners, fish processors, boat builders, fishing gear makers/repairers, retail traders and other casual income earners. Most people reside in temporary structures some occupied by more than one family. There are over 40 lodges (hotels) and 80 bars open $24 \mathrm{~h}$ a day throughout the week with young women whose main source of income is commercial sex There is also a large fish factory which processes and freezes fish and there is heavy traffic of freezer trucks which convey the frozen catch for export to Europe. All these groups have different contextual patterns of interactions, access to money and patterns of seasonal migration and engagement in sexual relationships that might affect their vulnerability to HIV acquisition. The majority of the adult population is not permanently married but has open and short term sexual relationships. Most sexual interactions entail a variety of financial relationships linked with the fishing industry and cuts across all age categories with a lot of cross generational sex. Kasensero landing site is also a social hub for singers from Kampala who are often accompanied by sex workers to attract clientele. Other social events such as film shows/drama groups are held almost daily.

The Kasensero fishing community is part of the Rakai Community Cohort (RCC). The RCC is a prospective cohort in Rakai that is surveyed every 12-15 months by the RHSP for demographic, HIV and reproductive data as well as other communicable and non communicable individual/family health indicators.

The community is served by two outpatient health facilities, one constructed and supported by the Rakai health sciences program (RHSP) and the other by government. Both facilities offer HIV testing and counseling (HTC), pre-antiretroviral (pre-ARV) care, and CD4 monitoring as well as antiretroviral therapy (ART) services every day from Monday to Friday and circumcision services through referrals to the main RHSP thaetre or through field outreach camps by the RHSP to kasensero at least once a quarter. There are ten drug shops/private clinics which are not officially accredited to offer ART but often sell cotrimoxazole, condoms and contraceptives all of which are important components of combination HIV prevention (DHO Un published).

\section{Data collection tools and methods}

This qualitative study employed 12 focus group discussions (FGDs) and 20 in depth interviews (IDIs). Participants were HIV infected and uninfected persons 15 years and older from the Kasensero community (Tables 1 and 2). The FGD and IDI participants were selected from a sampling frame designed to elicit different viewpoints [18]. The participants were chosen from all consenting members of the Rakai Community Cohort (RCC) through maximum variation sampling to capture differences of opinion with regard to age, gender, occupation and HIV transmission at Kasensero. The participants were also selected because they were considered to be more "knowledge rich" about the study topic [18]. Participants were invited to take part 
Table 1 General characteristics of in depth interviewees (IDIs)

\begin{tabular}{|c|c|c|c|}
\hline Variable & Category & No of participants & Percentage (\%) \\
\hline \multirow[t]{2}{*}{ Gender } & Male & 10 & 50 \\
\hline & Female & 10 & 50 \\
\hline \multirow[t]{2}{*}{ Marital status } & Married & 13 & 65 \\
\hline & Single & 07 & 35 \\
\hline Mean age & 29.7 & & \\
\hline \multirow[t]{4}{*}{ Age range } & $15-24$ & 08 & 40 \\
\hline & $25-34$ & 03 & 15 \\
\hline & $35-44$ & 08 & 40 \\
\hline & $45-54$ & 01 & 05 \\
\hline \multirow[t]{3}{*}{ Education } & None & 04 & 20 \\
\hline & Primary & 11 & 55 \\
\hline & Secondary & 05 & 25 \\
\hline \multirow[t]{4}{*}{ Religion } & Roman Catholic & 08 & 40 \\
\hline & Moslem & 05 & 25 \\
\hline & Protestant & 03 & 15 \\
\hline & Other & 04 & 20 \\
\hline \multirow[t]{9}{*}{ Occupation } & Fishing/fish trader & 09 & 45 \\
\hline & Bar owner & 02 & 10 \\
\hline & Student & 01 & 05 \\
\hline & Housewife & 03 & 15 \\
\hline & Motorcycle riding & 01 & 05 \\
\hline & Sex worker & 01 & 05 \\
\hline & Mechanic & 01 & 05 \\
\hline & Tailoring & 01 & 05 \\
\hline & Peasant farming & 01 & 05 \\
\hline
\end{tabular}

in only one FGD or IDI. Each FGD consisted of a maximum of 12 participants. The FGDs were stratified by gender and HIV status. Participants were not told how their groups were selected or their serostatus to avoid potential stigmatization and "playing to type". Having the information that people previously provided through the RCC surveys enabled us to choose the participants by characteristics such as occupation and HIV status.

Using a topic guide, we explored individual, network and group attitudes, risky behaviors, perceptions, misconceptions and other social contextual factors that were associated with the high HIV transmission in the area. On average, each interview lasted approximately one hour. Interviews stopped when it was judged that saturation had been reached.

All data collection was supervised and assessed by the first author (ML) who is a Ugandan public health physician experienced in social research for HIV care and the second author (NN) who is a social scientist with experience in qualitative research in the study setting. Five research assistants moderated and took notes for the study. The research assistants were conversant with qualitative data collection methods for over five years, had conducted similar research in the study setting and were fluent in Luganda (the local language). They were trained for two days on the study aim, design and tools. Role-plays were used to prepare the research assistants for their interaction with the informants $[19,20]$. The experiences from the role-plays were discussed and further methodological guidance was given. All the FGDs and the IDIs were conducted in Luganda, transcribed and later translated into English by the interviewers. The authors listened to the tapes to confirm the validity of the information. Data collection stopped when information relating to the topic guides revealed no new information.

\section{Data analysis}

Data analysis was iterative including reviews and discussions at different stages of data collection and appropriate modifications were made to the tools to address emerging issues [21, 22]. Content analysis was used to analyze the transcripts. This entailed reading and reviewing texts of the entire interview back and forth to identify meaningful units in relation to the study subject [21-24]. The meaningful units were condensed and coded by categories and themes individually by each of the authors. The authors then discussed their appropriate individual coding until

Table 2 General characteristics of FGD participants ( $n=92)$

\begin{tabular}{llll}
\hline Variable & Average characteristic of each FGD & Number & Percentage (\%) \\
\hline Participants Number & Average number per FGD & 7.7 & 15 to 65 years \\
Age & Age range per FGD & 68.2 min \\
Duration & Average duration per FGD & 06 & 50 \\
Sex & Males per FGD & 06 & 50 \\
& Females per FGD & 07 & 58 \\
HIV status mean & Positive per FGD & 05 & 42 \\
& Negative per FGD & & 58 \\
\hline
\end{tabular}


consensus was reached on the appropriate codes and the themes about the study subject [22].

\section{Ethical clearance}

The study was approved by the Uganda Virus Research Institute (UVRI) Science and Ethics Committee (SEC), and the Uganda National Council for Science and Technology (UNCST). We also sought the approval of the Rakai district authorities. As part of the informed consent, the participants were told about the aims of the study, the anticipated benefits and risks, their ability to participate or withdraw at any time, and assured that all information obtained would be kept confidential. For the minors, written informed consent for participation was sought from their guardians or next of kin who signed on their behalf. The participants signed two copies of the consent form before the interview commenced, and one copy was given to the participant.

\section{Results}

Our analysis of textual data generated eight themes including: (1) Service demand versus ART/circumcision disinhibition, (2) HIV depository, (3) Multiple partners, (4) Frequent unprotected sex, (5) Clothing, (6) Parental behaviors (7) Pressure within the sex industry and (8) Cross generational sex. We describe each of these themes in detail below.

\section{Service demand versus ARV/Circumcision disinhibition}

Most informants indicated that the demand for HIV prevention services at Kasensero was high. The informants reiterated that many members of the community sought HIV prevention services including ARVs and circumcision from the RHSP and government facilities at Kasensero because they had been told the services would prevent them from acquiring HIV.

"Many people here, even the ever busy fishermen have taken up circumcision and even RVs [ARVs] for those who have AIDS because they have been told these services can prevent them from acquiring or transmitting HIV." (HIV negative female informant, 27 years, bar owner)

From the accounts of a few informants, the demand for the services was unfortunately associated with a general lack of fear for HIV. Many informants held the view that people in Kasensero did not fear HIV because of the availability of ARVs which had in their view rejuvenated the lives of many of their colleagues from full blown AIDS to normal life. Others even held views that PLHIV who were on ARVs or had been circumcised were not infectious or could not be infected with HIV.
"The other reason for the high transmission is we no longer fear the disease (HIV)..... We have also seen friends here who were really badly off [too sick] but started ARVs and are now leaving a normal life. So this makes some people look at HIV just like any other disease such as malaria" (HIV negative, female fish traders FGD)

"....those who have been circumcised cannot infect others or even get infected themselves. It is like they have been immunized through the knife". (HIV positive female informant, 35 years, sex worker)

\section{HIV depository}

Since in Uganda HIV was first diagnosed at Kasensero as slim disease, there was a general perception across most informants that almost everybody in Kasensero was HIV positive and that no one could avoid becoming infected with HIV given the social and sexual dynamics at the site as cited by the FGD informants.

"But you know the other thing, Kasensero is a bank for $H I V$, since it was discovered here every widow or widower who has lost their spouses due to HIV run here because they are acceptable here.....I can assure you that everybody who comes here is HIV positive. So really we see not much cause for fearing what we already have". (HIV positive, 20-34 years FGD)

\section{Multiple partners}

Multiple partners was one of the reasons given for the high HIV transmission in Kasensesero. From the account of most informants, many people in Kansesero had several concurrent sexual partners depending on financial and social affordability. One man could reportedly have as many women as he could afford in a short period of time as long as he had the money. The women were also readily available to whoever could afford to sustain them, "...Even the women, are free on market who ever affords takes and keeps one until he is poor. So each man here has about five sex partners like in a month and the women about ten and these are not permanent because they keep changing with who is new in the area and who can afford. So from my view, it is promiscuity that has greatly contributed to the high HIV transmission and HIV prevalence." (HIV positive male informant, 41 years fisherman).

\section{Frequent unprotected sex}

Frequent un protected sex was often reported as one of the reasons for the high HIV transmission in Kasensero. Many men reportedly perceived sex with a condom as not being real and not satisfying. They therefore opted for unprotected sex at a little higher cost since the 
women were willing to give it to them for a little more money as reiterated by the sex workers.

"A man will give you any amount of money as long as it is unprotected sex. They say they don't really feel our sweetness when they are using condoms, they actually say it's not real sex because in reality, the man will be having sex with the condom and not you". (HIV positive female, sex workers FGD)

".....also no one should lie to you that a woman here in Kasensero, will ever refuse unprotected sex as long as she sees money in the hands. She will refuse initially just to bargain for more but eventually they accept and they also enjoy it" (HIV positive male informant, 19 years)

\section{Clothing}

As a bait to lure the money loaded fishermen men into sex, the sex workers reportedly dressed in a provocative or seducing way with very short skirts which almost revealed their private sex alluring parts or tight revealing attire. This dressing often enticed men into sex which in turn predisposed them to HIV acquisition as reported, by both sex workers and fishermen themselves.

"The other trick is timing when they have just come from the lake. Remember they are loaded with money, so we go and put on our miniskirts and seducing perfumes so every man will just be enticed. The moment you enter a bar like this you will certainly get a willing buyer. And these men are funny, he will tell you, for me I have survived the lake, so I want to enjoy you naturally ..." (HIV positive female informant, 28 years, sex worker)

"These girls put on very short skirts. You look at her brown thighs and immediately feel like doing anything to have sex with her, so you approach her, negotiate and then go for it." (HIV negative male, 20-34 FGD)

\section{Parental behaviors}

A few informants attributed the high HIV transmission to what they called "irresponsible parenting", particularly among the fisher folk and bar owners/barmaids. Some parents reportedly had sex in the presence of their children. Others even sent their young daughters out in the night so as to get space to have sex with their partners which in turn also exposed the daughters to dangerous sexual encounters outside their parents' houses/shelters. The informats felt that this behavior exposed teenage sons and daughters to HIV.
"The other big problem are the irresponsible parents. They bring in men or women for sex in their houses whether day or night in the presence of their children, so the children also get the impression that having sex is ok. Some even make funny noises during sex while their children are listening so what do you expect the children to do? They also copy the same behavior. "(HIV positive female, sex workers FGD)

"my mother asks me to get out to a friend's place until she calls me so they can have sex ..... in the process of finding where to stay I also find someone who can look after me for a night and here you don't look far.....

that is how I got into the sex network....". (HIV positive female informant, 19 years)

\section{Pressure within the sex industry}

Some informants attributed the high HIV transmission to risky sex behaviors ascribed to pressures from within the sex industry or an interested third party such as the bar owners. Many barmaids who also worked as sex workers had been brought to Kasensero by the "financially powerful" bar owners. The maids/sexworkers shelter, security and financial support were reportedly offered by the bar owners in exchange for loyalty including who the maids/sex workers had to have sex with protected or un protected which predisposed them to HIV as reiterated by some of the maids themselves.

"We don't get paid a salary, .......because she brought you from the village, the boss (bar owner) will instruct you on which of the approaching men you have to go and have sex with. Sometimes she tells you so and so has given us 200,000 UG shillings (76USD) so we shall divide equally, so I allow you to leave work now and go and have sex with him and you just have to accept or she (the bar owner) will fire you.". (HIV positive female informant, 35 years, bar maid)

\section{Cross generational sex}

Cross generation sex involving young girls and adult males and occasionally young men with older women in search for social, material support and other benefits was also often reported as a reason for the high HIV transmission. From the account of the informants, due to the nature and context of the sexual encounters in such relationships, normally the young beneficiaries were often compromised for choice, will and ability to practice safe sex or stick to one partner.

"You know all these young girls and boys are looking for money and they have little choice on nature of sex because they have to survive.... Old men can have sex with little girls because of money and then these young 
girls subsequently have sex with their age mates and vise-versa. The same boys will again have sex with others etc........ finally your child and the other ones in the community all acquire HIV from the same old man" (HIV positive, female fish traders FGD).

\section{Discussion}

Our findings suggest that the high HIV transmission in Kasensero is a complex function of positive/negative attitudes about HIV and CHP such as the demand for services versus ART/circumcision disinhibition and everyone in the community being potentially HIV positive. Multiple partners, frequent unprotected sex, clothing, parental behaviors, pressures within the sex industry and cross generation sex also contribute to the high HIV transmission in Kasensero.

There was a reported demand for circumcision and ART by the Kasesnsero community which fortunately are readily available at the site. The positive attitude or beliefs by the community in these services as a measure for CHP could be explained by the counselling given at the clinics and their community outreaches. It could also have been due to the frequent RHSP outreaches at the site and the recent demand generation activities promoting demedicalized CHP (the "stylish living" campaign). This finding is, however, contrary to other studies in Africa where fishing communities are faced with inaccessibility to care and poor demand for services [25-28]. The uptake and demand for the services is, however, complicated by the often (FGDs and IDIs) reported behavioral disinhibition related to ART and circumcision in the Kasensero community. The disinhibition could be explained by a lack of accurate HIV knowledge, social conventions or impulsivity. It could also have been due to risk compensation under which the people of Kasensero typically adjusted their behavior in response to the perceived reduced level of risk of acquiring HIV due to the presence of ART/circumcision. This finding is however contrary to other population based trials and/or meta-analyses in Rakai and other communities where ART availability and/or circumcision have not actually been found to cause changes into HIV risk behavior such as having unprotected sex [29-33]. The potential for disinhibition notwithstanding, it is important that the community demanded and took up circumcision and ART services as measures for HIV prevention. The readily available ART and circumcision services by the RHSP/government units at community bodes well especially at this time when global efforts are driven towards increased CHP for key populations [34]. The only challenge is how the access and availability of these services at the site can be sustained over time and extended to other nearby collaborating/interacting fishing communities while at the same time sensitizing the community against possible disinhibition. In terms of the social ecological model (SEM), this phenomenon clearly explains how individual, network or community perceptions or misconceptions about the importance of ART/circumcision affected their positive demand for the servies and yet still made them take up risky sexual behaviors.

Although some informants reiterated the uptake of ART and circumcision as HIV preventive measures, others thought they would inevitably acquire HIV because in their view, everyone in Kasensero was either HIV infected or had a very high risk of getting infected with HIV. This negative perception or attitude is likely to engender a sense of helplessness or lack of control to HIV preventive measures. The attitudes or misconceptions about HIV and CHP in these fishing communities (SEM) could be attributed to low levels of education, low social status and marginalization that has been described in similar resource poor settings [35-37]. The misconceptions about CHP methods or the inevitability of acquiring HIV has been reported among other key populations in Kenya and other resource poor settings [38-41].

Further, members in the Kasensero community had multiple extramarital sexual relationships a phenomenon that was socially acceptable. This predisposed them to several sexual encounters in a high HIV prevalence sexual network. Multiple sex partners have been found to increase potential for HIV acquisition or transmission by other studies in other fishing communities [3, 35, 42, 43].

Failure to use condoms in Kasensero could be attributed to the need for money that deprives women of the social bargaining power for safe protected sex and the relatively higher cost of unprotected commercial sex which makes it tempting for the economically vulnerable women to the young men with disposable income (SEM). It could also be attributed to frequent alcohol use and drug abuse that impair insight and judgment and facilitates behavioral disinhibition which are common in redundant fishing communities [44]. Other studies around the Lake Victoria basin have similarly found that the high HIV prevalence and transmission in fishing communities is attributed to the high rates of unprotected sex [35, 42, 45-48].

Short skirts and tight figure revealing clothing by sex workers or barmaids were used to attract the young fishermen for sex. This bait as the sex workers called it worked well especially to the redundant and money loaded fishermen who most likely have spent many days on the lake and are sexually starved. Seductive clothing as a driver for high HIV transmission has also been established in other studies in Africa and the middle east [49, 50].

The actions of some parents in Kasesero also exposed young girls to early sex. Many of these girls either heard or saw their parents have sex with casual partners while other parents sent the girls out at night so they could have sex in the houses with their casual sex partners. Sending the young girls out at night predisposed them to waiting 
men with money and subsequently to HIV. The effect of predisposing parental behaviors on HIV transmission has also been identified by UNAIDS and other studies in Africa [14, 39, 51-55].

The shelter, security and financial support for the bar maids were offered by the bar owners in exchange for loyalty. The bosses therefore decided which man the sex workers would have sex with, and how much they would charge for protected or unprotected sex. Because of their financial vulnerability, the sex workers lacked the social capital, security and bargaining power for safer sex or even the choice of who to have sex with regardless of the men's serostatus (SEM). Coercive working conditions have similarly been identified as drivers of high HIV transmission in several studies in Africa and Asia [56-58].

Related to this pressure within the sex industry was the cross generation sex involving young girls and adult males and occasionally young men with older women in search for social, material support and other benefits. Due to the nature and context of the sexual encounters in such relationships, normally the young beneficiaries are likely to be compromised for choice, will and ability to practice safe sex or stick to one partner. Cross generation sex has also similarly been identified as a driver for high HIV transmission in resource poor settings [59-62].

\section{Study limitations}

This study utilized in-depth interviews and focus groups. We did not conduct direct observation of bars or other entertainment venues where sex work frequently occurs. Such observations could have provided additional contextual perspective of what actually happens in these sexual engagements. However, the openness of our informants strengthens our confidence in the findings. We also triangulated our data collection methods (FGDs, IDIs). This helped us to check for consistency and contradictions inside and across the groups and interviewees. The multidisciplinary and native research team was useful in understanding the contextual aspects relating to high HIV transmission in Kasensero from the perspective of the community itself. We feel that the content analysis employed for this study has achieved appropriate in-depth analysis for the purpose of the study.

\section{Conclusions/Recommendations}

The current CHP services by the RHSP need to be enhanced with more government involvement including ensuring sustainable supply of ART and circumcision services since they are reportedly highly demanded. Community involvement through the engagement of popular peers could also help in the campaign to change the HIV predisposing culture, misconceptions, risky social norms and behaviors of the population.
Routine counselling about the effectiveness of the services against HIV transmission, however, needs to be done to avoid complacency and the disinhibition that could be associated with ART and circumcision.

\section{Competing interests}

The authors declare that they have no competing interests.

\section{Authors' contributions}

ML, NN, SN and SJR were involved in all the processes for the study from concept, design, data collection, analysis and interpretation of the findings. All the other authors contributed significantly to the data analysis and manuscript writing and intellectual content for the study. All authors read and approved the final manuscript.

\section{Acknowledgments}

I wish to acknowledge the support and skills provided by the research assistants. I also wish to acknowledge the cooperation and openness of the respondents.

We also wish to acknowledge funding for this study in part by the Division of Intramural Research, National Institute of Allergy and Infectious Diseases, National Institutes of Health (SJR), Rakai Health Sciences Program and Busoga University School of Graduate Studies.

\section{Author details}

${ }^{1}$ Rakai Health Sciences Program, Old Bukoba road, PO Box 279, Kalisizo, Uganda. 'Division of Global Health, IHCAR, Department of Public Health Sciences, Karolinsika Institutet, PO Box 1717007, Stockholm, Sweden. ${ }^{3}$ School of Graduate Studies and Research Busoga University, PO Box 154, Iganga, Uganda. ${ }^{4}$ Division of Intramural Research, National Institute of Allergy and Infectious Diseases, National Institutes of Health, Bethesda, MD, USA. ${ }^{5}$ Johns Hopkins University, Bloomberg School of Public Health, Baltimore, MD, USA.

Received: 16 March 2015 Accepted: 29 September 2015

Published online: 08 October 2015

\section{References}

1. UAC. Uganda HIV Modes of Transmission and Prevention Response Analysis. Kampala: Uganda AIDS Commission; 2009.

2. RHSP. Annual Preliminary report 2013. Kampala: Rakai health sciences program; 2013.

3. Opio A, Muyonga M, Mulumba N. HIV infection in fishing communities of Lake Victoria Basin of Uganda-a cross-sectional sero-behavioral survey. PLoS One. 2013:8:8e70770.

4. $\mathrm{MOH}$. Uganda AIDS Indicator Survey. Kampala: Ministry of Health; 2012.

5. Low N, Broutet N, Adu-Sarkodie Y, Barton P, Hossain M, Hawkes S. Global control of sexually transmitted infections. Lancet. 2006;368:2001-16.

6. Seeley J, Tumwekwase G, Grosskurth H. Fishing for a living and catching HIV: AIDS and changing patterns of the organisation of work in fisheries in Uganda. Anthropol Work Rev. 2009;30:66-76.

7. UAC. National HIV Prevention Strategy 2011-2015. Kampala: Uganda AIDS Commission; 2011.

8. Seeley J, Watts CH, Kippax S, Russell S, Heise L, Whiteside A. Addressing the structural drivers of HIV: a luxury or necessity for programmes? J Int AIDS Soc. 2012;15 Suppl 1:1-4.

9. Auerbach JD, Parkhurst JO, Caceres CF. Addressing social drivers of HIV/AIDS for the long-term response: conceptual and methodological considerations. Glob Public Health. 2011;6 Suppl 3:S293-309.

10. Gupta GR, Parkhurst JO, Ogden JA, Aggleton P, Mahal A. Structural approaches to HIV prevention. Lancet. 2008;372:764-75.

11. Hargreaves JR, Slaymaker E, Fearon E, Howe LD. Changes over time in sexual behaviour among young people with different levels of educational attainment in Tanzania. J Int AIDS Soc. 2012;15 Suppl 1:1-7.

12. MacPherson EE, Sadalaki J, Njoloma M, Nyongopa V, Nkhwazi L, Mwapasa V, et al. Transactional sex and HIV: understanding the gendered structural drivers of HIV in fishing communities in Southern Malawi. J Int AIDS Soc. 2012;15 Suppl 1:1-9.

13. UNAIDS. Practical guidelines for intensifying HIV prevention. Towards universal access. Geneva: UNAIDS; 2007.

14. UNAIDS. Global report on the global AIDS epidemic. Geneva: UNAIDS; 2010. 
15. UNAIDS. Combination HIV Prevention: Tailoring and Coordinating Biomedical, Behavioural and Structural Strategies to Reduce New HIV Infections. Geneva: UNAIDS; 2010.

16. McLeroy KR, Bibeau D, Steckler A, Glanz K. An ecological perspective on health promotion programs. Health Educ Q. 1988;15:351-77.

17. Sallis JF, Owen N, Fisher EB. Ecological models of health behavior. Health behavior and health education. Theory, research, and practice. 2008;465-486.

18. Boyden E. A manual for participatory research with children. Stockholm: Wiley Inter-science; 1997.

19. Fleury J, Lee SM. The social ecological model and physical activity in African American women. Am J Community Psychol. 2006;37:129-40.

20. Henderson NR. Managing moderator stress. Take a deep breath. You Can Do this. Mark Res. 2009;21:28-9.

21. Stewart DW, Shamdasani PN, Rook DW. Focus groups: theory and practice. Oaks: Sage Publications; 2007

22. Morse F. Qualitative research methods for health professionals. Oaks: Sage Publications; 1995.

23. Dahlgren L, Emmelin M, Winkvist A. Qualitative methodology for international public health. Umea: Umea University; 2004.

24. Holloway. A-Z of qualitative research in health care. secondth ed. Oxford: Blackwell Publishers; 2008.

25. Seeley JA, Allison EH. HIV/AIDS in fishing communities: challenges to delivering antiretroviral therapy to vulnerable groups. AIDS Care. 2005;17:688-97.

26. Mugisha E, van Rensburg GH, Potgieter E. Factors influencing utilization of voluntary counseling and testing service in Kasenyi fishing community in Uganda. J Assoc Nurses AIDS Care. 2010;21:503-11.

27. Mugisha E, van Rensburg GH, Potgieter E. Strategic framework for increasing accessibility and utilization of voluntary counseling and testing services in Uganda. AIDS Res Treat. 2011;2011:912650.

28. Commission LVB. HIV Sero-Behavioural Study in the Fishing Communities along Lake Victoria in Uganda. Kampala: Lake Victoria Basin; 2010.

29. Agot KE, Kiarie JN, Nguyen HQ, Odhiambo JO, Onyango TM, Weiss NS. Male circumcision in Siaya and Bondo Districts, Kenya: prospective cohort study to assess behavioral disinhibition following circumcision. J Acquir Immune Defic Syndr. 2007:44:66-70.

30. Doyle JS, Degenhardt L, Pedrana AE, McBryde ES, Guy RJ, Stoove MA, et al. Effects of HIV antiretroviral therapy on sexual and injecting risk-taking behavior: a systematic review and meta-analysis. Clin Infect Dis. 2014;59:1483-94.

31. Kong X, Kigozi G, Nalugoda F, Musoke R, Kagaayi J, Latkin C, et al. Assessment of changes in risk behaviors during 3 years of posttrial follow-up of male circumcision trial participants uncircumcised at trial closure in Rakai, Uganda. Am J Epidemiol. 2012;176:875-85.

32. Westercamp N, Agot K, Jaoko W, Bailey RC. Risk compensation following male circumcision. Results from a two-year prospective cohort study of recently circumcised and uncircumcised men in Nyanza Province, Kenya. AIDS Behav. 2014;18:1764-75.

33. Gray R, Kigozi G, Kong X, Ssempiija V, Makumbi F, Wattya S, et al. The effectiveness of male circumcision for HIV prevention and effects on risk behaviors in a posttrial follow-up study. AIDS. 2012;26:609-15.

34. UNAIDS. Treatment 2015; demand, invest, deliver. Geneva: WHO/UNAIDS/ UNICEF; 2013.

35. Kiwanuka N, Ssetaala A, Mpendo J, Wambuzi M, Nanvubya A, Sigirenda S, et al. High HIV-1 prevalence, risk behaviours, and willingness to participate in HIV vaccine trials in fishing communities on Lake Victoria, Uganda. J Int AIDS Soc. 2013;16:18621.

36. Mazzeo. Dynamics of HIV/AIDS in the Fishing Communities of Benin and Uganda. Rome: Food and Agriculture Organization, HIV/AIDS Program; 2004.

37. Yaya I, Saka B, Landoh DE, Patchali PM, Makawa MS, Senanou S, et al. Sexual risk behavior among people living with HIV and AIDS on antiretroviral therapy at the regional hospital of Sokode, Togo. BMC Public Health. 2014;14:636.

38. Voeten HA, Egesah OB, Ondiege MY, Varkevisser CM, Habbema JD. Clients of female sex workers in Nyanza province, Kenya. A core group in STD/HIV transmission. Sex Transm Dis. 2002;29:444-52.

39. Kalichman SC, Simbayi L. Traditional beliefs about the cause of AIDS and AIDS-related stigma in South Africa. AIDS Care. 2004;16:572-80.

40. Thanavanh B, Harun-Or-Rashid M, Kasuya H, Sakamoto J. Knowledge, attitudes and practices regarding HIV/AIDS among male high school students in Lao People's Democratic Republic. J Int AIDS Soc. 2013;16:17387.

41. Pickering H, Okongo M, Bwanika K, Nnalusiba B, Whitworth J. Sexual behaviour in a fishing community on Lake Victoria, Uganda. Health Transit Rev. 1997;7:13-20.
42. Asiki G, Mpendo J, Abaasa A, Agaba C, Nanvubya A, Nielsen L, et al. HIV and syphilis prevalence and associated risk factors among fishing communities of Lake Victoria, Uganda. Sex Transm Infect. 2011;87:511-5.

43. Béné C, Merten S. Women and Fish-for-Sex. Transactional Sex, HIV/AIDS and Gender in African Fisheries. World Dev. 2008;36:875-99.

44. Choudhry V, Agardh A, Stafstrom M, Ostergren PO. Patterns of alcohol consumption and risky sexual behavior: a cross-sectional study among Ugandan university students. BMC Public Health. 2014;14:128.

45. Kiwanuka N, Ssetaala A, Nalutaaya A, Mpendo J, Wambuzi M, Nanvubya A, et al. High incidence of HIV-1 infection in a general population of fishing communities around Lake Victoria, Uganda. PLoS One. 2014;9, e94932.

46. Bajunirwe F, Bangsberg DR, Sethi AK. Alcohol use and HIV serostatus of partner predict high-risk sexual behavior among patients receiving antiretroviral therapy in South Western Uganda. BMC Public Health. 2013;13:430.

47. Santos GM, Emenyonu NI, Bajunirwe F, Rain Mocello A, Martin JN, Vittinghoff E, et al. Self-reported alcohol abstinence associated with ART initiation among HIV-infected persons in rural Uganda. Drug Alcohol Depend. 2014;134:151-7.

48. Seeley J, Grellier R, Barnett T. Gender and HIV/AIDS impact mitigation in sub-Saharan Africa-recognising the constraints. SAHARA J. 2004;1:87-98.

49. Massad SG, Karam R, Brown R, Glick P, Shaheen M, Linnemayr S, et al. Perceptions of sexual risk behavior among Palestinian youth in the West Bank: a qualitative investigation. BMC Public Health. 2014;14:1213.

50. Tanzarn N. Bishop-Sambrook: The dynamics of HIV/Aids in smallscale fishing communities in Uganda. Rome: FAO; 2003.

51. Campbell T, Bernhardt S. Factors that contribute to women declining antenatal HIV testing. Health Care Women Int. 2003;24:544-51.

52. FOCUS. HVI/AIDS situation analysis in Malawi. Blantyre: Foundation for Communnity Support Services; 2012.

53. Gordon CM, Forsyth AD, Stall R, Cheever LW. Prevention interventions with persons living with HIV/AIDS: state of the science and future directions. AIDS Educ Prev. 2005;17:6-20.

54. Lwenya Y. The Fisherman's wife: vulnerabilities and strategies in the local economy. The Case of Lake Victoria, Kenya Signs. 2012;37:566-73.

55. Campbell C, Skovdal M, Gibbs A. Creating social spaces to tackle AIDS-related stigma: reviewing the role of church groups in Sub-Saharan Africa. AIDS Behav. 2011;15:1204-19.

56. Wirth KE, Tchetgen Tchetgen EJ, Silverman JG, Murray MB. How does sex trafficking increase the risk of HIV Infection? An observational study from Southern India. Am J Epidemiol. 2013;177:232-41.

57. Kathleen Wirth. The role of sex trafficking in HIV. Gaborone; www.nytimes.com/roomfordebate/2013/11/28/how-will-aids-be-eradicated/ the-role-of-sex-trafficking; 2013.

58. Sarkar K, Bal B, Mukherjee R, Chakraborty S, Saha S, Ghosh A, et al. Sex-trafficking, violence, negotiating skill, and HIV infection in brothel-based sex workers of eastern India, adjoining Nepal, Bhutan, and Bangladesh. J Health Popul Nutr. 2008;26:223-31.

59. UNAIDS. Facing the Future Together: Report of the Secretary Generals' Task Force on Women, Girls, and HIV/AIDS in Southern Africa. Geneva: UNAIDS; 2004.

60. UNAIDS. UNAIDS, Report on the Global AIDS Epidemic, Joint United Nations Programme on HIV/AIDS. Geneva: UNAIDS; 2006.

61. Gregson S, Nyamukapa CA, Garnett GP, Mason PR, Zhuwau T, Carael M, et al. Sexual mixing patterns and sex-differentials in teenage exposure to HIV infection in rural Zimbabwe. Lancet. 2002;359:1896-903.

62. Boily MC, Lowndes CM, Gregson S. Population-level risk factors for HIV transmission and 'the 4 cities study. Temporal dynamics and the significance of sexual mixing patterns. AIDS. 2002;16:2101-2. 